Supporting Information to

\title{
Anti-Biofouling Isoporous Silica-Micelle Membrane Enabling Drug Detection in Human Whole Blood
}

\author{
Qinqin Sun, Fei Yan, Lina Yao and Bin Su*
}

Institute of Analytical Chemistry, Department of Chemistry, Zhejiang University, Hangzhou 310058, China

* Corresponding author. E-mail: subin@zju.edu.cn

\section{Table of Content}

S1. Experimental details

S1.1 Chemicals and materials

S1.2 Electrodes (iSMM/ITO and iSM/ITO) preparation

S1.3 Chloramphenicol analysis

S1.4 Apparatus and methods

S2. Comparison of different methods for detection of CAP

S3. TEM and SEM characterization of iSMM

S4. Voltammetric responses of four probes at the iSM/ITO electrode

S5. EIS results of FcMeOH at different electrodes

S6. Optimized preconcentration time for electrochemical detection of CAP

S7. Calibration curves of ITO and iSM/ITO in human whole blood

S8. Calibration curves of ITO and iSMM/ITO in $0.9 \mathrm{wt} \% \mathrm{NaCl}$ 


\section{S1. Experimental details}

\section{S1.1 Chemicals and Materials}

All chemicals of analytical grade were used as received without further purification. Milli-Q water $(18 \mathrm{M} \Omega \mathrm{cm}$ ) was used to prepare all aqueous solutions. Tetraethoxysilane (TEOS, $\geq 99.0 \%$ ) and hexaammineruthenium (III) chloride $\left(\mathrm{Ru}\left(\mathrm{NH}_{3}\right)_{6} \mathrm{Cl}_{3}, 98.0 \%\right)$ were bought from Sigma-Aldrich. Cetyltrimethylammonium bromide $(\mathrm{CTAB}, \geq 98.0 \%)$ and hydroxymethylferrocene $(\mathrm{FcMeOH}$, 97.0\%) were purchased from Alfa-Aesar. Ammonia aqueous solution (25 $\mathrm{wt} \%$, potassium ferricyanide $\left(\mathrm{K}_{3} \mathrm{Fe}(\mathrm{CN})_{6}\right)$, chloramphenicol (CAP, 98.0\%; its structure is shown in Figure S1) and rutin were obtained from Aladdin (Shanghai, China). Human whole blood samples were kindly donated by the Hospital of Zhejiang University, which were kept in a heparinized tube to prevent from clotting. Indium tin oxide (ITO) glass (surface resistance $<17 \mathrm{ohm} /$ square) was ordered from Zhuhai Kaivo Optoelectronic Technology Co. Ltd. (China). Prior to use, it was first treated with 1 mol L $\mathrm{L}^{-1} \mathrm{NaOH}$ aqueous solution, then ultrasonically cleaned in acetone, ethanol and water for 20 min sequentially, and finally dried with argon.<smiles>O=C(N[C@H](CO)[C@H](O)c1ccc([N+](=O)[O-])cc1)C(Cl)Cl</smiles>

Figure S1. The molecule structure of CAP

\section{S1.2 Electrodes (iSMM/ITO and iSM/ITO) Preparation}

The iSMM was synthesized by the modified Stöber-solution growth method $^{1}$. CTAB $(0.16 \mathrm{~g})$ and ultrapure water $(70 \mathrm{~mL})$ were mixed with anhydrous ethanol $(30 \mathrm{~mL})$, to which the concentrated ammonia aqueous solution $(2.5 \mathrm{wt} \%, 100 \mu \mathrm{L})$ and TEOS $(80 \mu \mathrm{L})$ were added dropwise under mild 
stirring. After mixing homogeneously, 12 pieces of freshly cleaned ITO glass $(2.5 \mathrm{~cm} \times 5.0 \mathrm{~cm})$ were immersed into the above solution under quiescent condition at $60{ }^{\circ} \mathrm{C}$ in a water bath for 24 h. After rinsing thoroughly with copious amount of water and aging at $100{ }^{\circ} \mathrm{C}$, the iSMM was formed on the ITO surface, denoted as iSMM/ITO. The iSM/ITO was obtained by immersing the iSMM/ITO in ethanol solution containing $0.1 \mathrm{M} \mathrm{HCl}$ for 5 min under magnetically stirring.

\section{S1.3 Chloramphenicol Analysis}

Stock solution of CAP in ethanol with a concentration of $5 \mathrm{mg} \mathrm{mL} \mathrm{m}^{-1}$ was diluted by mixing with ultrapure water to different concentrations $\left(1 \mathrm{mg} \mathrm{mL}^{-1}\right.$ and $\left.0.1 \mathrm{mg} \mathrm{mL} \mathrm{m}^{-1}\right)$. Sodium chloride aqueous solution $(0.9 \mathrm{wt} \% \mathrm{NaCl})$ was utilized as the supporting electrolyte throughout the CAP detection experiment. Before each measurement, the solutions were bubbled by argon for at least 20 min and the accumulation of CAP in micelles was carried out by mechanically stirring at 400 rpm for $30 \mathrm{~s}$. The concentrations of CAP were determined using the standard addition method, in a concentration range from 0.1 to $15.0 \mathrm{ppm}$, namely $0.1,0.2,0.3,0.5,0.7,1.0,2.0,3.0,4.0,5.0$, 7.0, 10.0 and $15.0 \mathrm{ppm}$.

\section{S1.4 Apparatus and Methods}

For all electrochemical measurements, a conventional three-electrode configuration, consisting of a working electrode (bare ITO, iSM/ITO or iSMM/ITO, with a geometric surface area of 0.25 $\left.\mathrm{cm}^{2}\right)$, an $\mathrm{Ag} / \mathrm{AgCl} / 3 \mathrm{M} \mathrm{KCl}$ reference electrode and a platinum grid auxiliary electrode $\left(4 \mathrm{~cm}^{2}\right)$, was employed. Electrochemical impedance spectroscopy (EIS) was conducted on Autolab PGSTAT302N workstation (Metrohm, Switzerland). The impedance data was measured at the formal potential with a small amplitude sinusoidal ac bias $(10 \mathrm{mV})$ in the frequency range from 10 
$\mathrm{MHz}$ to $0.1 \mathrm{~Hz}$. The obtained complex impedance plots were fitted using the Autolab Nova software. All equivalent circuits proposed in this work are the best fitted ones with the error, $\chi^{2}$, lower than 0.09, in terms of the complex nonlinear least-squares (CNLS) ${ }^{2}$.

Cyclic voltammetry (CV) and differential pulse voltammetry (DPV) were performed on a CHI660D electrochemical workstation (Chenhua, Shanghai, China). For DPV, the parameters were used as follows: amplitude $(0.05 \mathrm{~V})$, pulse width $(0.2 \mathrm{~s})$ and pulse period $(0.5 \mathrm{~s})$, in all measurements.

The scanning electron microscopy (SEM) image was captured on a SU8010 field-emission scanning electron microscope (Hitachi, Japan) and the samples were coated with a thin layer of gold before imaging. The accelerating voltage was $3.0 \mathrm{kV}$ for the whole blood adhesion test and $8.0 \mathrm{kV}$ for characterization the thickness of the iSMM. The top-view transmission electron microscopy (TEM) image was obtained on a HT7700 microscope (Hitachi, Japan) operated at 100 $\mathrm{kV}$. The TEM specimen was prepared by peeling iSMM film from the ITO with a clean blade. After sonication in ethanol, the dispersion was dropped on a copper grid. 


\section{S2. Comparison of different electrochemical methods for detection of CAP}

\begin{tabular}{|c|c|c|c|c|c|}
\hline Electrode & Method & Range (M) & LOD $(\mathrm{M})$ & Sample ${ }^{\mathrm{a}}$ & Ref. \\
\hline iSMM & DPV & $3.1 \times 10^{-7} \sim 4.6 \times 10^{-5}$ & $1.2 \times 10^{-7}$ & Whole blood & This work \\
\hline Electrochemical activated carbon fiber microelectrode & SWV & $1.0 \times 10^{-7} \sim 1.0 \times 10^{-5}$ & $4.7 \times 10^{-8}$ & P-milk & 3 \\
\hline Nitrogen-doped graphene nanosheets decorated with gold nanoparticles & LSV & $2.0 \times 10^{-6} \sim 8.0 \times 10^{-5}$ & $5.9 \times 10^{-7}$ & CAP eye drops & 4 \\
\hline Carbon nanotube-gold nanoparticles-ionic liquid composite & LSV & $1.0 \times 10^{-8} \sim 6.0 \times 10^{-6}$ & $5.0 \times 10^{-9}$ & P-milk & 5 \\
\hline Carbon nanotube-CTAB-poly(diphenylamine) & DPV & $1.0 \times 10^{-8} \sim 1.0 \times 10^{-5}$ & $2.0 \times 10^{-9}$ & P-Milk, P-honey & 6 \\
\hline a The alphabet "P" in this line represents "Processed". & & & & & \\
\hline
\end{tabular}

The analytical performance of different electrochemical methods for the detection of CAP was summarized at Table S1. The response range and LOD of CAP at the iSMM/ITO was comparable with other materials, even for the direct detection in the human whole blood. 


\section{S3. TEM and SEM characterization of iSMM}
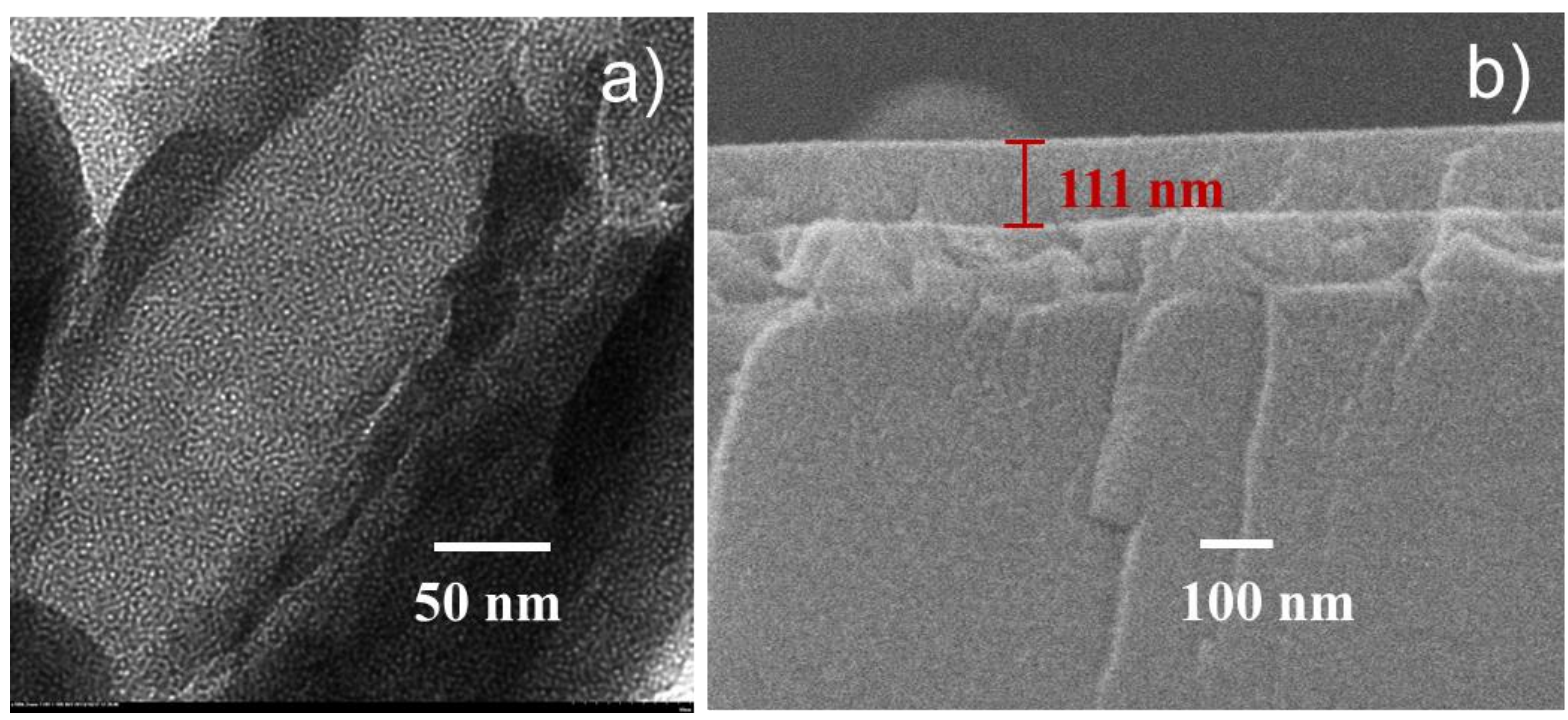

Figure S2. (a) TEM image of iSMM showing the mesopores as the bright spots. (b) Crosssectional SEM image illustrating the iSMM layer on the ITO electrode with a thickness of $c a .111$ $\mathrm{nm}$ (showed as red line)

The structure and the morphology of iSMM were characterized by SEM and TEM. From the top-view of TEM image, the iSMM film consisted of plentiful mesopores over a large scale, with the diameter of ca. $2.3 \mathrm{~nm}$ (Figure S2a). The SEM image in Figure S2b exhibited three layers, namely, iSMM (111 nm), indium tin oxide (100 nm) layer and glass, from top to bottom. 


\section{S4. Voltammetric responses of four probes at the iSM/ITO electrode}
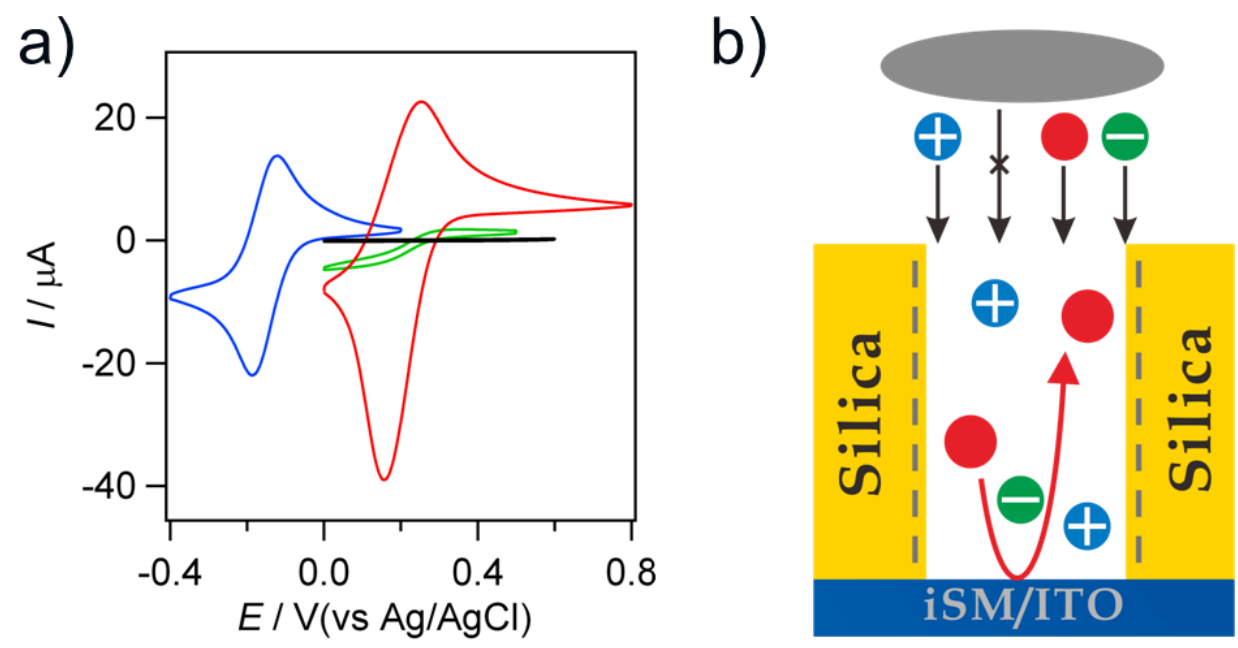

Figure S3. (a) CVs of $0.5 \mathrm{mM} \mathrm{Ru}\left(\mathrm{NH}_{3}\right)_{6}{ }^{3+}$ (blue line), $\mathrm{Fe}(\mathrm{CN})_{6}{ }^{3-}$ (green line), $\mathrm{FcMeOH}$ (red line) and $40 \mu \mathrm{M}$ Rutin (black line) at the iSM/ITO. Scan rate: $50 \mathrm{mV} \mathrm{s}^{-1}$. (b) Schematic illustration of the electrochemical behaviors of different probes at the iSM/ITO.

After the removal of CTAB from the isoporous silica membrane (iSM), the ITO was exposed to the electrolyte. Hence, all small-sized redox probes, namely negatively charged $\mathrm{Fe}(\mathrm{CN})_{6}{ }^{3-}$, positively charged $\mathrm{Ru}\left(\mathrm{NH}_{3}\right)_{6}{ }^{3+}$ and neutral $\mathrm{FcMeOH}$, can access to and react at the underlying ITO surface. However, large hydrophobic molecule, e.g. rutin, was excluded by the iSM due to the size-selectivity. 


\section{S5. EIS results of $\mathrm{FcMeOH}$ at different electrodes}
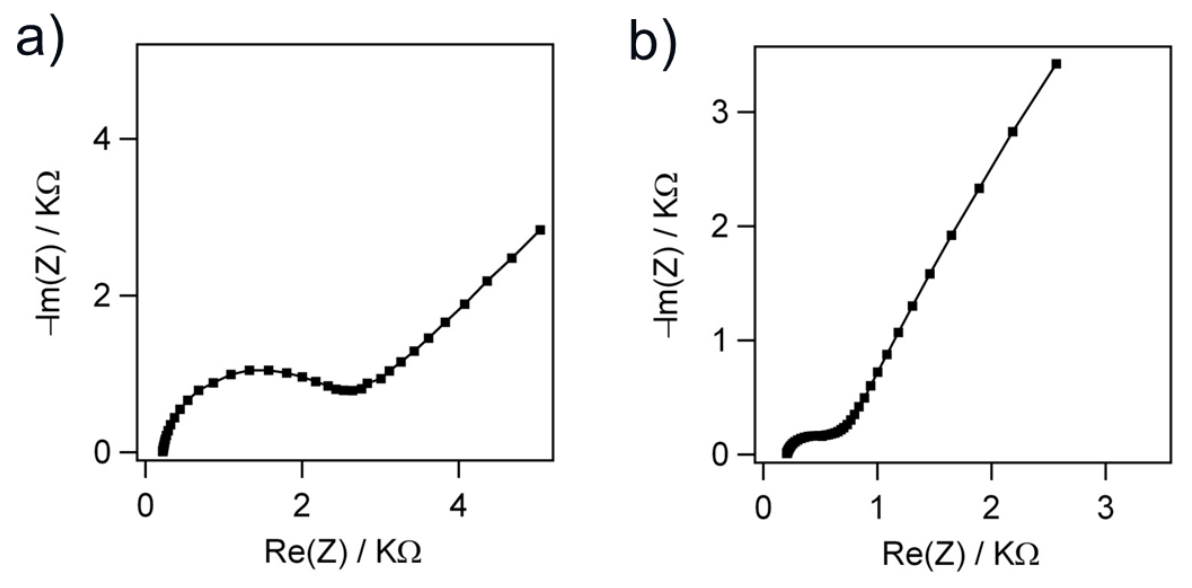

c)

d)
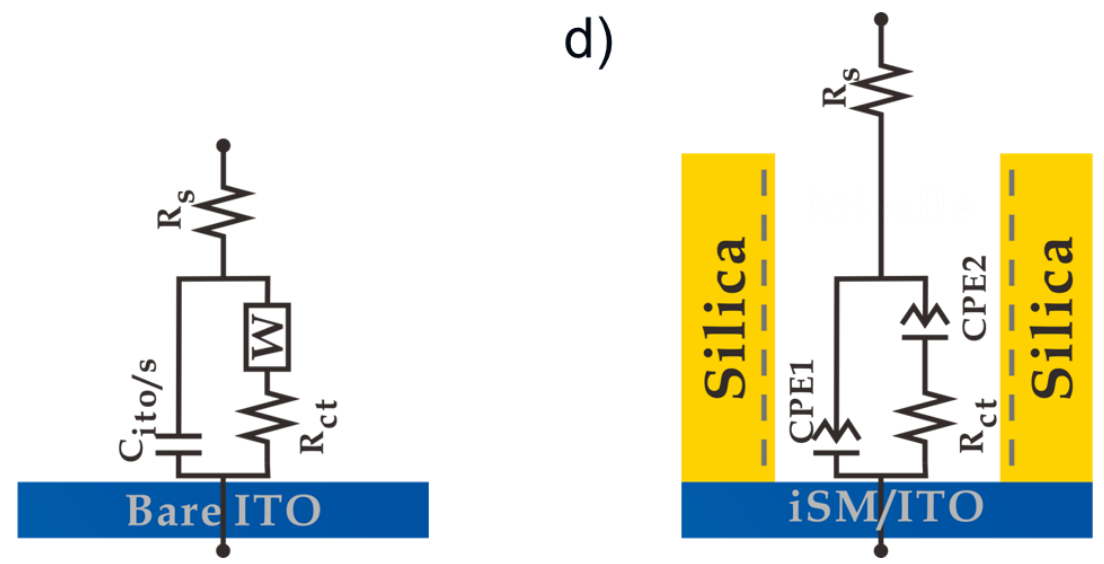

Figure S4. Nyquist plots of $0.5 \mathrm{mM} \mathrm{FcMeOH}$ at (a) ITO, (b) iSM/ITO. The best fitted equivalent circuit models of (c) ITO and (d) iSM were shown. The supporting electrolyte was 0.1 $\mathrm{M} \mathrm{KCl}$.

The impedance responses of $\mathrm{FcMeOH}$ at different electrodes (bare ITO, iSM/ITO and iSMM/ITO) and the related equivalent circuit models by fitting the measured data were shown in Figures S4. The best fitted equivalent circuit models of FcMeOH at bare ITO and iSM/ITO (Figures $\mathrm{S} 4 \mathrm{c}$ and $\mathrm{S} 4 \mathrm{~d}$ ) consist of the series resistance $\mathrm{R}_{\mathrm{s}}$, the parallel combination a capacitor $C_{\mathrm{ito} / \mathrm{s}}$ (or constant phase element CPE1) with a charge-transfer resistance $R_{\mathrm{ct}}$ and mass-transport related Warburg element $\mathrm{W}$ (or CPE2). The element $R_{\mathrm{ct}}, \mathrm{W}$ and $\mathrm{R}_{\mathrm{s}}$ represent the charge-transfer resistance, mass-transfer related Warburg element and the uncompensated resistance of electrolyte, 
respectively. $C_{\mathrm{ito} / \mathrm{s}}$ denotes the double layer capacitance at the ITO/solution interface. CPE is the constant phase element with the expression, $Z_{\mathrm{CPE}}(\omega)=\frac{1}{Y_{0}(\mathrm{j} \omega)^{n}}(n=0$, the CPE represents the resistor, $n=1$ the capacitor, and $n=0.5$ the Warburg element). By contrast, the circuit for FcMeOH at the iSMM/ITO electrode (as shown in Figure 1d) consists of another element associated with the micelle/solution interface, namely $C_{\mathrm{m} / \mathrm{s}}$, proving the extraction process of FcMeOH into the micelle phase.

Table S2 Summary of the circuit element values for different electrodes in $0.1 \mathrm{M} \mathrm{KCl}$ containing $0.5 \mathrm{mM} \mathrm{FcMeOH}$

\begin{tabular}{|c|c|c|c|c|}
\hline \multirow{2}{*}{\multicolumn{2}{|c|}{ Element }} & \multicolumn{3}{|c|}{ Electrode } \\
\hline & & ITO & iSM & iSMM \\
\hline \multicolumn{2}{|l|}{$R_{\mathrm{s}}(\Omega)$} & 226 & 225 & 226 \\
\hline \multicolumn{2}{|c|}{$R_{\mathrm{ct}}(\Omega)$} & 1937 & 460 & 188 \\
\hline \multicolumn{2}{|c|}{$C_{\text {ito/s }}$ or $C_{\text {ito } / \mathrm{m}}(\mu \mathrm{F})$} & 2.16 & & 1.42 \\
\hline \multicolumn{2}{|c|}{ Warburg $\left(\mu \mathrm{Mh}_{0}\right)$} & 300 & & 321 \\
\hline \multirow[t]{2}{*}{ CPE1 } & $Y_{\mathrm{o}}\left(\mu \mathrm{Mh}_{0}\right)$ & & 13.2 & \\
\hline & $n$ & & 0.78 & \\
\hline \multirow[t]{2}{*}{ CPE2 } & $Y_{\mathrm{o}}\left(\mu \mathrm{Mh}_{0}\right)$ & & 343 & \\
\hline & $n$ & & 0.68 & \\
\hline \multicolumn{2}{|c|}{$C_{\mathrm{m} / \mathrm{s}}(\mathrm{mF})$} & & & 1.02 \\
\hline
\end{tabular}

The element values, obtained by closest fitting the experimental data to the corresponding equivalent circuits, were summarized in Table $\mathrm{S} 2$. The significantly smaller $\mathrm{R}_{\mathrm{ct}}$ for FcMeOH at the iSMM/ITO electrode (namely $188 \Omega$ ), compared to those at a bare ITO and iSM/ITO (namely $1937 \Omega$ and $466 \Omega$, respectively), is indicative of an accelerated electron transfer at the iSMM/ITO electrode. These impedance data show the priority of the iSMM film for the detection of lipophilic targets in aqueous media. 
Additionally, the $n$ values for CPE1 and CPE2 were 0.78 and 0.68 respectively. The values indicate that the CPE elements resemble neither the resistor $(n=0)$ nor the capacitor $(n=1)$. We speculate that the phenomenon arises from the difference in the mass transport of $\mathrm{FcMeOH}$ and $\mathrm{FcMeOH}^{+}$. The Si-OH groups on the iSM surface can be deprotonated to bear negatively charges when the solution $\mathrm{pH}$ was higher than its isoelectric point $(2 \sim 3)^{7}$, and the mass transport of $\mathrm{FcMeOH}^{+}$can be enhanced by electrostatic interaction but that of $\mathrm{FcMeOH}$ not. 


\section{S6. Optimized preconcentration time for electrochemical detection of CAP}

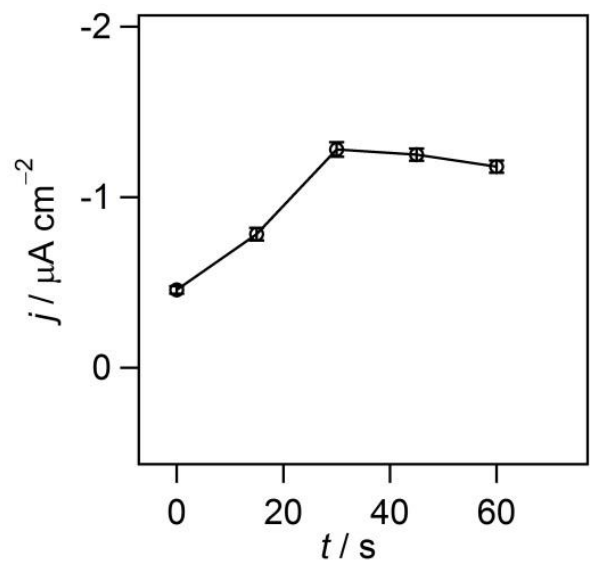

Figure S5. Influence of the mechanical stirring time on the electrochemical response of $1 \mathrm{ppm}$ CAP at the iSMM/ITO electrode in the heparinized whole blood diluted by 10 times with 0.9 wt $\% \mathrm{NaCl}$. The stirring speed was $400 \mathrm{rpm}$.

Mechanical stirring was selected as the preconcentration method to extract the CAP from aqueous solution into micelles in order to enhance the sensitivity. As displayed in Figure S5, the reduction current increased with increasing the stirring time. And the current keep unchanged when the preconcentration time was above $30 \mathrm{~s}$, indicating the extraction/preconcentration of CAP in the micelles reached equilibrium. So mechanical stirring (400 rpm) for $30 \mathrm{~s}$ was applied to extract the CAP from the bulk solution before the electrochemical detection. 


\section{S7. Calibration curves of ITO and iSM/ITO in human whole blood}
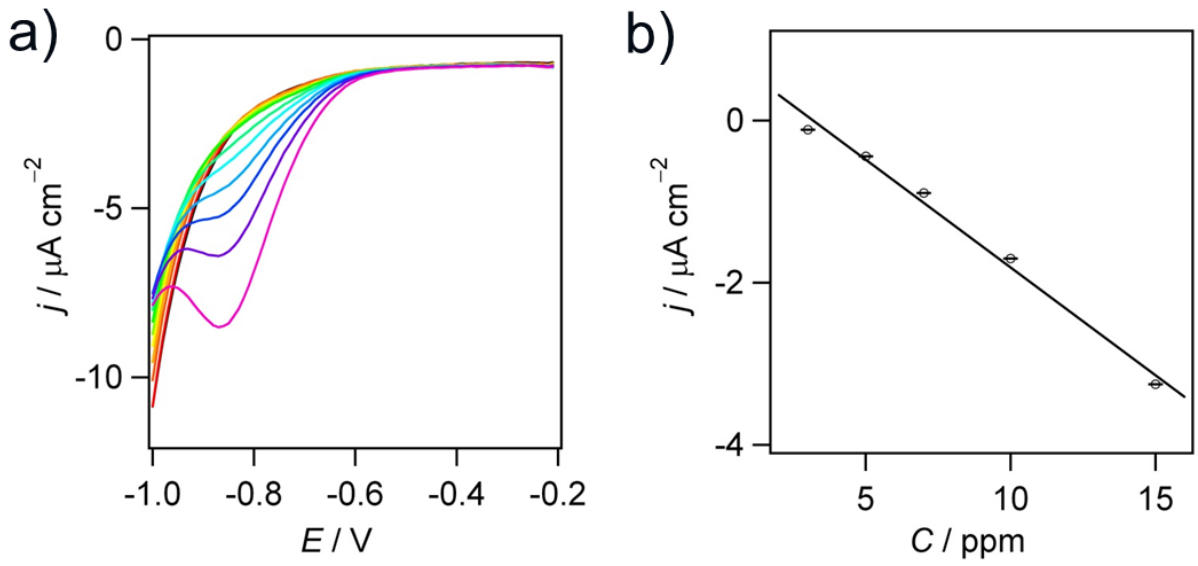

Figure S6. (a) DPVs of an iSM/ITO electrode in the heparinized whole blood diluted by 10 times with $0.9 \mathrm{wt} \% \mathrm{NaCl}$; (b) The calibration curve of CAP.

In human whole blood samples, the reduction peak current of CAP at the iSM/ITO was also gradually increased with increasing the concentration of CAP, as shown in Figure S6a. The calibration curve by plotting the current response versus the CAP concentration was presented in Figure S6b. The linear fitting yielded a sensitivity of $-0.27 \mu \mathrm{A} \mathrm{cm} \mathrm{ppm}^{-1}$ in the range from 3 ppm to $15 \mathrm{ppm}$. And the limit of detection (LOD), with a value $1623.9 \mathrm{ppb}$, is much higher than that of iSMM/ITO (37.7 ppb), indicating that the pre-concentration ability of micelles favored the trace analysis in real/complex samples. 

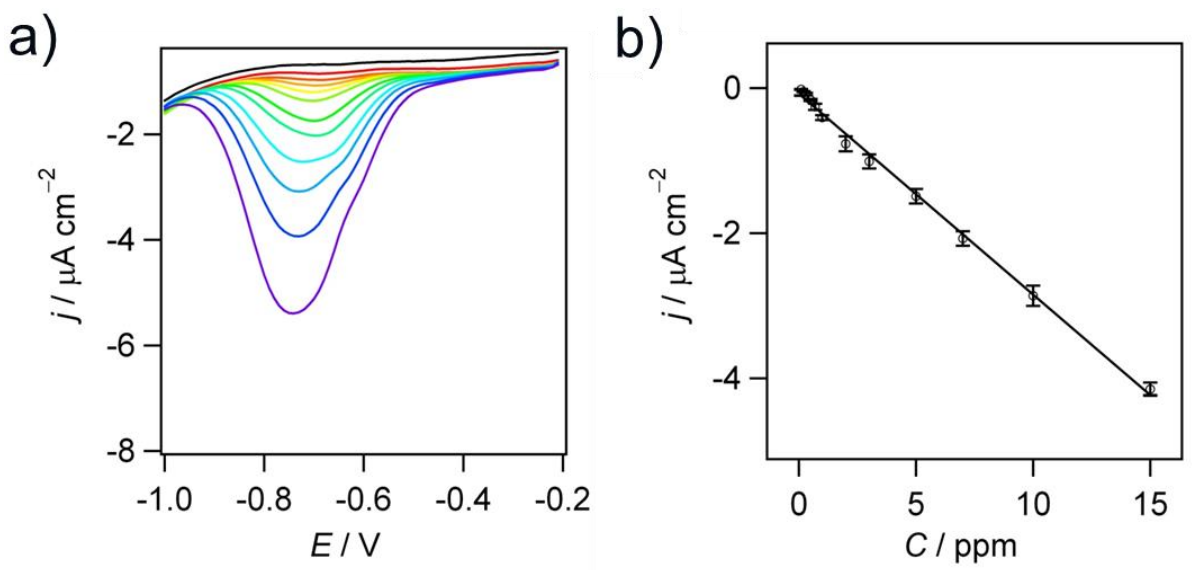

Figure S7. (a) DPVs of an ITO electrode in the heparinized whole blood diluted by 10 times with $0.9 \mathrm{wt} \% \mathrm{NaCl}$; (b) The calibration curve of CAP. Error bars represent the standard deviation, $\mathrm{n} \geq 3$.

In human whole blood samples, the broaden reduction peak current of CAP at the bare ITO was also gradually increased with increasing the concentration of CAP, as shown in Figure S7a. The calibration curve by plotting the current response versus the CAP concentration was presented in Figure S7b. The linear fitting yielded a sensitivity of $-0.28 \mu \mathrm{A} \mathrm{cm}^{-2} \mathrm{ppm}^{-1}$ and LOD of 160.8 ppb. 


\section{S8. Calibration curves of ITO and iSMM/ITO in $0.9 \mathrm{wt} \% \mathrm{NaCl}$}
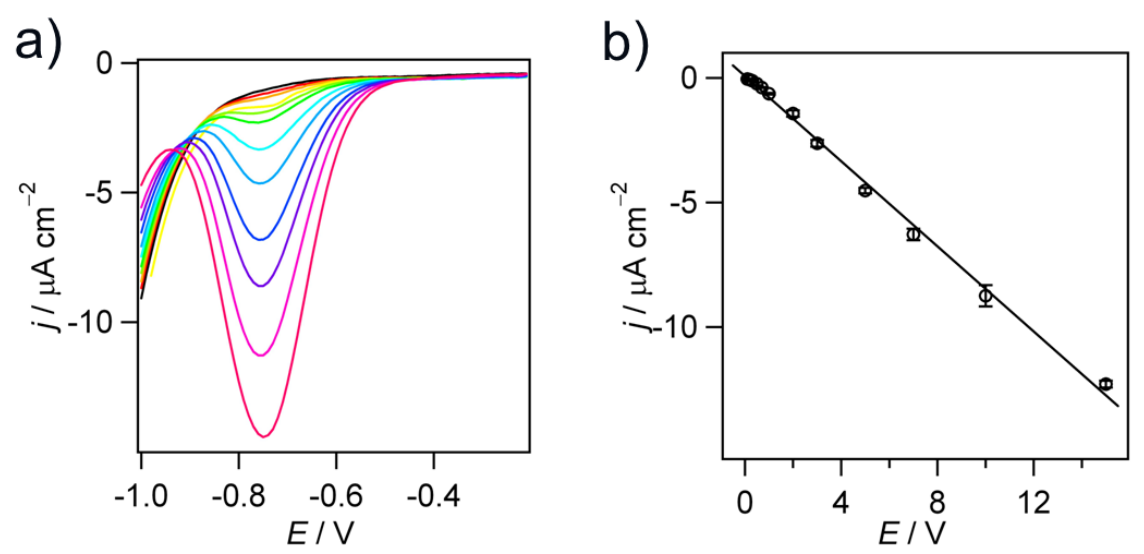

Figure S8 (a) DPVs of a bare ITO in $0.9 \mathrm{wt} \% \mathrm{NaCl}$ upon successive addition of CAP; (b) The calibration curve of CAP. Error bars represent the standard deviation, $n \geq 3$.
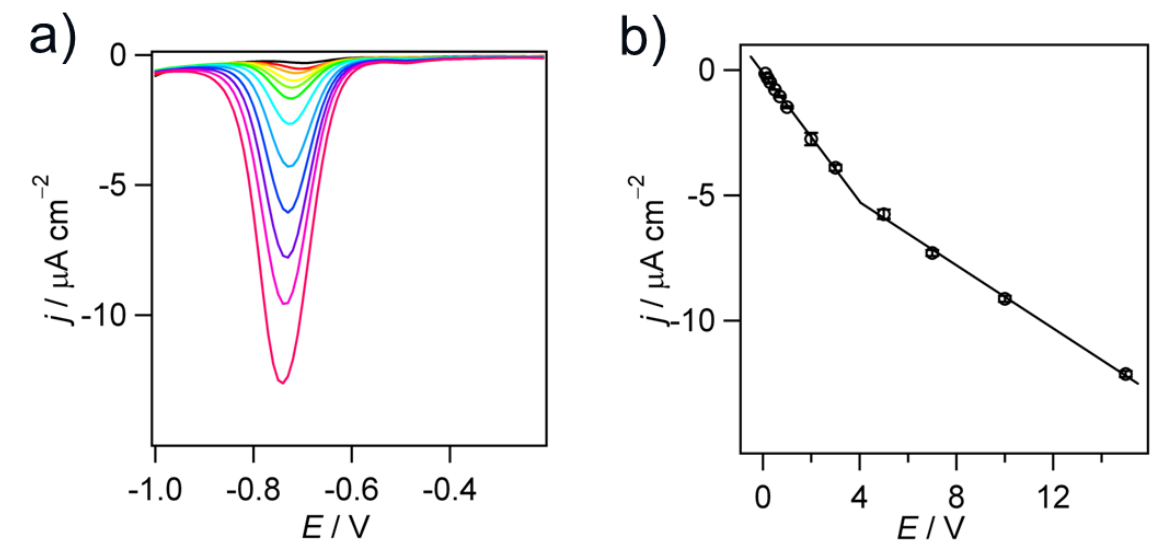

Figure S9 (a) DPVs of an iSMM/ITO in $0.9 \mathrm{wt} \% \mathrm{NaCl}$ upon successive addition of CAP; (b)

The calibration curve of CAP. Error bars represent the standard deviation, $\mathrm{n} \geq 3$. 
Table S3. The analytical results of ITO and iSMM/ITO electrodes for the detection of CAP in $0.9 \mathrm{wt} \% \mathrm{NaCl}$

\begin{tabular}{llccc} 
Electrode & $\begin{array}{l}\text { Sensitivity } \\
\left(\mu \mathrm{A} \mathrm{cm} \mathrm{ppm}^{-1}\right)\end{array}$ & Range $(\mathrm{ppm})$ & LOD $(\mathrm{ppb})$ & $R^{2}$ \\
\hline iSMM/ITO & $-1.29 \pm 0.03$ & $0.1-4.0$ & $10.8 \pm 0.2$ & 0.998 \\
& $-0.63 \pm 0.01$ & $4.0-15.0$ & & 0.998 \\
ITO & $-0.86 \pm 0.01$ & $0.1-15.0$ & $64.8 \pm 0.1$ & 0.996 \\
\hline
\end{tabular}

In $0.9 \mathrm{wt} \% \mathrm{NaCl}$ aqueous solutions, apparent current responses were also displayed at both bare ITO (Figure S8a) and iSMM/ITO (Figure S9a). The reduction peak current gradually increased with the addition of analyte. The calibration curve by plotting the current response versus the CAP concentration was presented in Figures $\mathbf{S} 8 \mathrm{~b}$ and $\mathrm{S} 9 \mathrm{~b}$. The analytical results were summarized in Table S3. 


\section{REFERENCES}

(1) Teng, Z.; Zheng, G.; Dou, Y.; Li, W.; Mou, C.-Y.; Zhang, X.; Asiri, A. M.; Zhao, D. Angew. Chem. Int. Ed. 2012, 51, 2173-2177.

(2) Orazem, M. E.; Tribollet, B. Electrochemical Impedance Spectroscopy; John Wiley \& Sons, 2008.

(3) Agüí, L.; Guzmán, A.; Yáñez-Sedeño, P.; Pingarrón, J. M. Anal. Chim. Acta 2002, 461, 65-73.

(4) Borowiec, J.; Wang, R.; Zhu, L.; Zhang, J. Electrochim. Acta 2013, 99, 138-144.

(5) Xiao, F.; Zhao, F.; Li, J.; Yan, R.; Yu, J.; Zeng, B. Anal. Chim. Acta 2007, 596, 79-85.

(6) Kor, K.; Zarei, K. J. Electroanal. Chem. 2014, 733, 39-46.

(7) Etienne, M.; Quach, A.; Grosso, D.; Nicole, L.; Sanchez, C.; Walcarius, A. Chem. Mater. 2007, 19, 844-856. 